\title{
Synthesis, DFT, Molecular docking Analysis and Antibacterial, Antioxidant Activities of tri- substituted pyrazoles
}

\author{
Rachid Chebaki ${ }^{1}$, Lynda Golea ${ }^{2 *}$, Youcef Boumedjane ${ }^{1}$ and Soumia Bouzidi ${ }^{3}$ \\ ${ }^{1}$ Laboratory of Molecular Chemistry and Environment (LCME), Computer and Pharmaceutical Chemistry Team (ECIP), \\ Faculty of Sciences and Exact Sciences - Department of Material Sciences, University of Biskra, BP 145 RP, 07000 \\ Biskra, Algeria \\ ${ }^{2}$ Department of Material Science, Faculty of Science and Technology, Abbes Laghrour University, 40000 Khenchela,
} Algeria

${ }^{3}$ Laboratory for Biotechnology of Bioactive Molecules and Cell Pathophysiology, Department of Organism Biology, Faculty of Nature and Life Sciences, University of Batna 2, Algeria

\begin{abstract}
Pyrazole and its derivatives are contemplated crucial compounds in heterocyclic chemistry which are also used extensively in organic synthesis. These cycles are known for their biological and pharmacological activities. The present investigation is in the interest of some synthesized derivatives containing the pyrazole moieties. (5-Hydroxy-3,5-dimethyl-4,5-dihydro-pyrazol-1-yl)pyridin-4-yl-methanone (1) and Furan-2-yl-(5-hydroxy-3,5-dimethyl-4,5-dihydro-pyrazol-1-yl)methanone (2) were synthesized by cyclocondensation of the 1,3-dicarbonyl with the hydrazine derivative with a simple and rapid approach to obtain substituted pyrazole. All structures of these compounds were elucidated by spectral ( ${ }^{1} \mathrm{H}$ NMR and ${ }^{13} \mathrm{C} \mathrm{NMR}$ ) analysis. The antibacterial activity of the synthesized compounds was screened against two Gram-positive and Gram-negative bacteria, and all of them displayed moderate activity. The radical scavenging activity of these compounds were evaluated using 1,1-diphenyl-2-picrylhydrazyl (DPPH), the synthetic compounds showed moderate antioxidant activities. In addition, the results obtained from antibacterial activity were further explained with the help of DFT and molecular orbital calculations with a basis set 6$311+\mathrm{G}(\mathrm{d}, \mathrm{p})$. The synthesized compounds were docked with 6RKV enzymes with the use molecular docking tools and the docking results are explained all interactions amino acid residue of enzyme and compounds.
\end{abstract}

Keywords: Pyrazole; biological activities; DFT; NMR; molecular docking

\section{INTRODUCTION}

Pharmaceutical research on the natural products represents a major strategy for the discovery and the development of new substances with therapeutic interest. The pyrazole or pyrazoline nucleus has many biological activities and medical properties such as antibacterial (Nimbalkar \& Hote, 2015), sedative-hypnotic, antifungal (Karrouchi et al., 2018), anticonvulsant, antiviral, antiparasitic (Shah et al., 2011) anti-tubercular and insecticidal (Flores et al., 2014). 1,3,5-
Trisubstituted pyrazoles constitute a number of drugs including sildenafil, celecoxib, rimonabant and difenamizole (Khan et al., 2016). In view of the interest in the activity of pyrazole and its derivatives, and in continuation of our research on the synthesis of new compounds of biological and pharmacological interest, we interested herein the preparation, biological activity, DFT and molecular docking studies of tri-substituted pyrazoline. It is also known in the literature that the synthesis of 1,3,5-trisubstituted pyrazoles are synthesized by cyclocondensation of hydrazines with 
diketones in acidic medium (Venkateswarlu et al., 2018). here we use the method described in reference (Arfan et al., 2009) we use silica gel and to synthesize our products (1) and (2). all synthesized compounds have studied for antimicrobial activities against selected bacterial as strains by the agar well diffusion method. Free radical scavenging activity has been investigated by using DPPH method. all the synthesized compounds, (1) and (2) exhibited moderate antibacterial and antioxidant activities.

\section{MATERIALS AND METHODS}

\section{A. Solvents and Materials}

All solvents and chemicals were used as received and without any purification, then FT-IR spectra were performed on JASCO FT/IR-4100. ${ }^{1} \mathrm{H}-\mathrm{NMR}$ and ${ }^{13} \mathrm{C}-$ NMR spectra were recorded in deuteron $\mathrm{MD}_{3} \mathrm{OD}$ or $\mathrm{CDCl}_{3}$ on a Fourier ARX 400 spectrometer at $400 \mathrm{MHz}$ for proton and $100 \mathrm{MHz}$ for Carbon 13. Chemical shifts ( $\delta$ ) are given in ppm and $J$ values in Hertz (Hz). Thinlayer chromatography (TLC) was carried out on precoated Merck silica gel $60 \mathrm{~F}_{254}$. Melting points were determined on an Electro thermal capillary fine control apparatus which are uncorrected.

\section{RESULT AND DISCUSSION}

\section{B. Chemistry}

The synthesis of method is depicted in (Figure 1). Title compounds are synthesized using the previously reported method (Arfan et al., 2009). It is known in the work of the literature that the condensation reaction of acetylacetone and hydrazine derivatives in ethanol and catalyzed by acetic acid directly give the corresponding pyrazole ring, but when the reaction medium is changed by the addition of silica gel, the majority products (1) and (2) are obtained; we can explain that this method is stopped at the alcohol function and does not pass to the stage of elimination of water. Here examining the pharmacological profile of the hydroxyl group, we synthesize the pyrazole substituted by the hydroxyl function and also study their biological properties, named antiabacterial and antioxidant activities.

\section{A.1. Synthesis of (5-Hydroxy-3,5-dimethyl-4,5-dihydro-} pyrazol-1-yl)-pyridin-4-yl-methanone (1)

White powder, 70\% yield, m.p. $128-130^{\circ} \mathrm{C}$, IR (KBr): $v 3229$ (OH), $2928(\mathrm{CH}), 1626(\mathrm{C}=\mathrm{O}), 1546(\mathrm{C}=\mathrm{N}) \mathrm{cm}^{-1} \cdot{ }^{1} \mathrm{H}$ NMR (400 $\left.\mathrm{MHz}, \mathrm{CDCl}_{3}\right): \delta=1.96\left(\mathrm{~s}, 3 \mathrm{H}, \mathrm{CH}_{3}\right), 2.02\left(\mathrm{~s}, 3 \mathrm{H}, \mathrm{CH}_{3}\right)$, $3.04\left(\mathrm{dd}, 2 \mathrm{H}, \mathrm{CH}_{2}\right), 7.87$ (s, $2 \mathrm{H}$, pyridine), $8.81(\mathrm{~s}, 2 \mathrm{H}$, pyridine). ${ }^{13} \mathrm{C} \mathrm{NMR}\left(100 \mathrm{MHz}, \mathrm{CDCl}_{3}\right.$ ): $\delta=166.04,156.51$, 149.70, 141.74, 123.35, 92.81, 51.12, 26.71, 16.18. Anal. Calcd for $\mathrm{C}_{11} \mathrm{H}_{13} \mathrm{~N}_{3} \mathrm{O}_{2}: \mathrm{C}, 70.26 ; \mathrm{H}, 5.98 ; \mathrm{N}, 19.17 ; \mathrm{O}, 14.60$.

A.2. Synthesis of Furan-2-yl-(5-hydroxy-3,5-dimethyl-4,5dihydro-pyrazol-1-yl)-methanone (2)

Yellow powder, $68 \%$ yield, m. p. $112-115^{\circ} \mathrm{C}$, IR (KBr): $v 3340$ $(\mathrm{OH}), 2989(\mathrm{CH}), 1636(\mathrm{C}=\mathrm{O}), 1545(\mathrm{C}=\mathrm{N}) \mathrm{cm}^{-1} \cdot{ }^{1} \mathrm{H}$ NMR (400 MHz, $\left.\mathrm{MD}_{3} \mathrm{OD}\right): \delta=2.09\left(s, 3 \mathrm{H}, \mathrm{CH}_{3}\right), 2.24\left(s, 3 \mathrm{H}, \mathrm{CH}_{3}\right)$, 3.00-3.04 (dd, $\left.2 \mathrm{H}, \mathrm{CH}_{2}\right), 6.78(s, 1 \mathrm{H}$, furan), $7.89(s, 1 \mathrm{H}$, furan), 8.12 ( $s, 1 \mathrm{H}$, furan). ${ }^{13} \mathrm{C} \mathrm{NMR}$ (100 $\left.\mathrm{MHz}, \mathrm{MD}_{3} \mathrm{OD}\right): \delta=$ $156.31,152.63,149.19,145.44,124.63,113.11$, 90.80, 51.10, 24.01, 14.60. Anal. Calcd for $\mathrm{C}_{10} \mathrm{H}_{12} \mathrm{~N}_{2} \mathrm{O}_{3}$ : C, 57.68; H, 5.81; $\mathrm{N}, 13.45 ; \mathrm{O}, 23.05$.
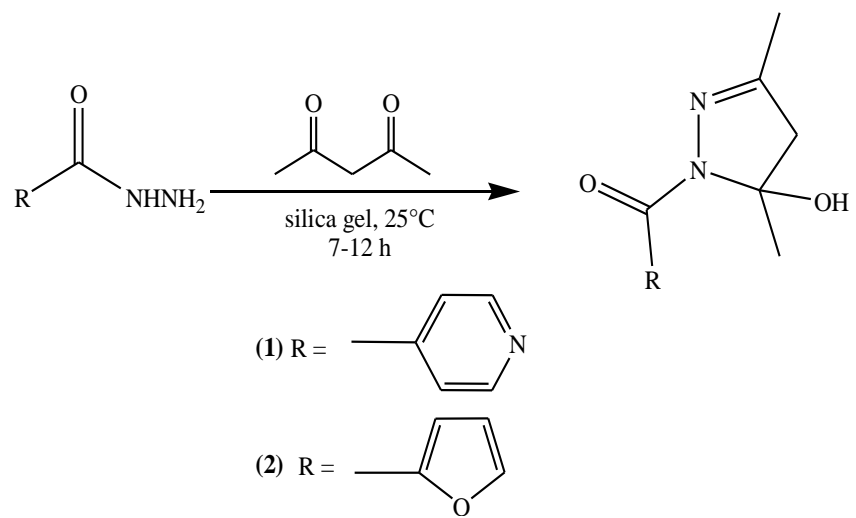

Figure 1. Synthesis of compounds (1) and (2)

\section{Antibacterial activity}

The title compounds were tested against three standard bacterial strains for the determination of their antibacterial activity, against a variety of bacterial strain such as Escherichia coli ATCC 25922, Staphylococcus aureus ATCC 25923 and Pseudomonas aeruginosa ATCC 27853 using dimethyl sulfoxide (DMSO) as a solvent. The agar well diffusion method was used to determine antimicrobial activity (Celikel \& Kavas, 2009). Similarly, the impregnated disks were placed on the medium suitably spaced apart and the plates were then incubated at $5^{\circ} \mathrm{C}$ for 1 hour to permit good diffusion. After that, they were transferred to an 
incubator at $37^{\circ} \mathrm{C}$ for 24 hours for bacteria. The antibacterial activity was evaluated by measuring the inhibition zone diameter observed. Standard drugs like Ampicillin, Gentamycin were also used for comparison purpose.

Compounds (1) and (2) reported here were evaluated for their antibacterial activities against Escherichia coli, Staphylococcus aureus and Pseudomonas aeruginosa. Zone inhibition values were measured in millimeters. data on the antibacterial activities of the title compounds are given in (Table 1). The values of these inhibitory zones reveal that the compounds exhibit moderate antibacterial activities against all microbial strains at concentrations of 50 and $100 \mu \mathrm{g} / \mathrm{mL}$, respectively. The biological activity of these compounds results from the presence of the pyrazole, pyridine and furan rings which play a very important role in elucidating the mechanism of transformation reaction in biological systems. The DMSO control showed no antimicrobial activity against the bacterial strains tested, while the test compound was found to be active.

Table 1. Antibacterial activity of compound (1) in an agar diffusion test

\begin{tabular}{|c|c|c|c|c|c|}
\hline & Comp & und (l) & Coms & und (2) & AMP \\
\hline & $100 \mu \mathrm{g} / \mathrm{ml}$ & $50 \mu \mathrm{g} / \mathrm{ml}$ & $100 \mu \mathrm{g} / \mathrm{ml}$ & $50 \mu \mathrm{g} / \mathrm{ml}$ & $\begin{array}{c}10 \\
\mu \mathrm{g} / \mathrm{dis}\end{array}$ \\
\hline E.coli & $11,42 \pm 0,64$ & $9,00 \pm 1,12$ & $13,01 \pm 0,98$ & $12,25 \pm 1,22$ & 28 \\
\hline S.alleells & $10,78 \pm 1,58$ & $8,57 \pm 1,08$ & $12,28 \pm 1,52$ & $11,33 \pm 2,08$ & 14 \\
\hline P.aurellgenosa & $10,69 \pm 1,02$ & $8,33 \pm 1,52$ & $12,66 \pm 1,52$ & $11,48 \pm 1,52$ & 19 \\
\hline
\end{tabular}

Zone of inhibition in mm: < 10: week; > 10: moderate; >16: Significant AMP: Ampicillin

GEN: Gentamycin

Values are the average of three replicates.

\section{Antioxidant activity}

The antioxidant potential of any compound can be determined on the basis of its scavenging activity of the stable 2,2-diphenyl-1-picrylhydrazyl (DPPH) free radical as described by (Leitao et al., 2002). Stock solutions of samples were prepared by dissolving $10 \mathrm{mg}$ of synthesized samples in $10 \mathrm{ml}$ of methanol to give a concentration of $1 \mathrm{mg} / \mathrm{ml}$. Then prepared sample concentrations of $5,15,25,30,40$ and 50 $\mu \mathrm{g} / \mathrm{ml}$. The methanol solution of DPPH (20 $\mathrm{mg} / \mathrm{l}$ ) was prepared daily. The mixtures were made by adding $100 \mu \mathrm{l}$ of test sample to $900 \mu \mathrm{l}$ of DPPH solution. Ascorbic acid was used as standard (o-30 $\mu \mathrm{g} / \mathrm{ml})$. These solution mixtures were kept in dark for 30 min and optical density was measured at $517 \mathrm{~nm}$ using the spectrophotometer. The optical density was recorded and \% of inhibition was calculated using the formula given below:

Percent (\%) inhibition of DPPH activity $=100 \times(\mathrm{A}-\mathrm{B}) / \mathrm{A}$

Where $\mathrm{A}=$ optical density of the blank and $\mathrm{B}=$ optical density of the sample

The $\mathrm{IC}_{50}$ value was calculated by linear regression of plots where the abscissa represented the concentration of the title compounds and compared with the standard reference compound ascorbic acid. The statistical analyze were performed by a Microsoft Excel 2007 and all the numerical results were expressed graphically.

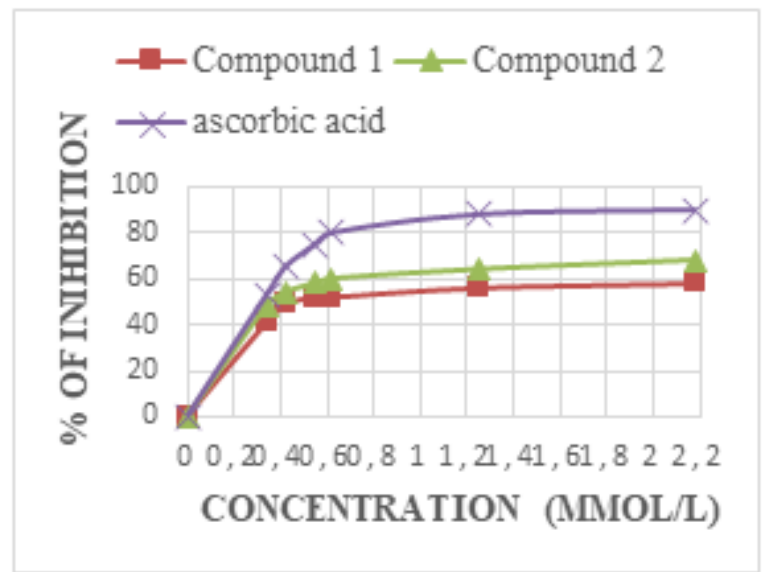

Figure 2. Antioxidant activity results using DPPH

The obtained results indicated that synthesized compounds (1) and (2) showed a good antioxidant activity with value of $\mathrm{IC}_{50} 56.10$ and $59.16 \mu \mathrm{g} / \mathrm{ml}$. These values were nearly close to standard ascorbic acid with IC50 value $37.10 \mu \mathrm{g} / \mathrm{ml}$ from regression equation in (Figures 2). all compounds indicating the excellent scavenging activity because the presence of the hydroxyl group in the structures may be responsible for trapping the free radical DPPH.

\section{E. Computational study}

All quantum chemical studies were performed with the Gaussian package 09 (Frisch et al., 2003). Gauss View 5.08 (Dennington et al., 2008) has been used for the visualization of the structure and The optimized geometry and electronic structure of the title compounds in the gas phase were carried out using the Density Functional Theory (DFT) with hybrid functional B3LYP, based on Becke's three-parameter 
functional, including Hartree-Fock exchange contribution with a nonlocal correction for the exchange potential proposed by Becke together with the nonlocal correction for the correlation energy provided by (Lee et al., 1988). with the basic set 6-311+G (p, d) (Gonzalez et al., 1990). The values of HOMO, LUMO energies and global reactivity such as chemical potential $(\mu)$, hardness $(\eta)$, were calculated using Koopman's theorem was determinate (Zhan et al., 2003) to relate the HOMO and LUMO energies to the IP and EA, respectively:

$$
\mathrm{IP}=-\mathrm{E}_{\mathrm{HOMO}} \text {, and } \mathrm{EA}=-\mathrm{E}_{\mathrm{LUMO}}
$$

The electronegativity ( $\mathrm{X}$ ), defined by (Mulliken et al., 1934) as the average of (IP) and (EA):

$$
\chi=(\mathrm{IP}+\mathrm{EA}) / 2
$$

Chemical hardness is a useful concept to understand the reaction of chemical systems and is associated with the stability and reactivity of a chemical system (Pearson et al., 1985). Chemical hardness can be calculated as follows: $\eta=$ (IP - EA) /2. The softness of a molecule is calculated by: $S=$ $1 / 2 \eta$. Electronic energy calculation values of title compounds are summarized in (Table 2).

Table 2. Theoretical results of compounds (1) and (2)

\begin{tabular}{c|c|cc|cc|c|c}
\hline Compound & $\begin{array}{c}\text { HOMO } \\
(\mathrm{eV})\end{array}$ & $\begin{array}{c}\text { LUMO } \\
(\mathrm{eV})\end{array}$ & $\begin{array}{c}\text { Energy } \\
\text { gap } \\
(\mathrm{eV})\end{array}$ & $\begin{array}{c}\mu \\
(\mathrm{D})\end{array}$ & $\begin{array}{c}(\boldsymbol{\gamma}) \\
(\mathrm{eV})\end{array}$ & $\begin{array}{c}(\mathrm{\eta}) \\
(\mathrm{eV})\end{array}$ & $\begin{array}{c}(\mathbf{S}) \\
(\mathrm{eV})\end{array}$ \\
\hline $\mathbf{( 1 )}$ & -6.35 & -1.96 & 4.39 & 6.51 & 4.15 & 2.19 & 0.23 \\
\hline $\mathbf{( 2 )}$ & -6.40 & -2.95 & 3.45 & 4.24 & 4.76 & 1.73 & 0.29 \\
\hline
\end{tabular}

According to the electrostatic results illustrated in (Table 2) have been explained with respect to the experimental biological activity of the compounds synthesized. The compound (2) shown a LUMO energy of $-2.95 \mathrm{eV}$ is biologically active compared to the compound (1) of $-1.96 \mathrm{eV}$. The values of biological activity between the two compounds can be explained by the difference in LUMO energy levels. LUMO energy represents the ability to accept an electron that is related to electron affinity (Gece, 2008). The difference energy between HOMO and LUMO characterizes their chemical stability. Farther, energy is used to estimate the limiting electron density by predicting the most reactive position in $\pi$-electron systems. It is also used to explain several types of reactions in conjugate systems (Choi \& Kertesz, 1997). It has been observed that compounds with higher LUMO orbitals have remarkable biological activity. This difference in energy compared to the LUMO orbitals can be explained by the furan and pyridine heterocycles. the oxygen atom is more electronegativity than the nitrogen atom therefore the furan ring reactivates than pyridine which clearly indicates that the electronegativity plays an important role in the stability of LUMO orbitals which has an influence on the biological activity. In addition, quantum studies have shown that the energy values of HOMO can be an indicator of antioxidant activity, of which we note in (Table 2) the values of the HOMO orbitals between the two compounds (1) and (2) very close to one of the other which shows that they have good antioxidant activity with $\mathrm{IC}_{50}$ between 56.10 and $59.16 \mu \mathrm{g} / \mathrm{ml}$. which also proves the influence of the substituents on the pyrazole ring mainly the hydroxyl group.
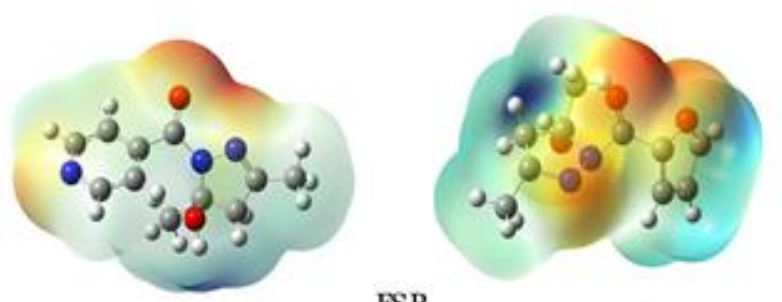

ESP
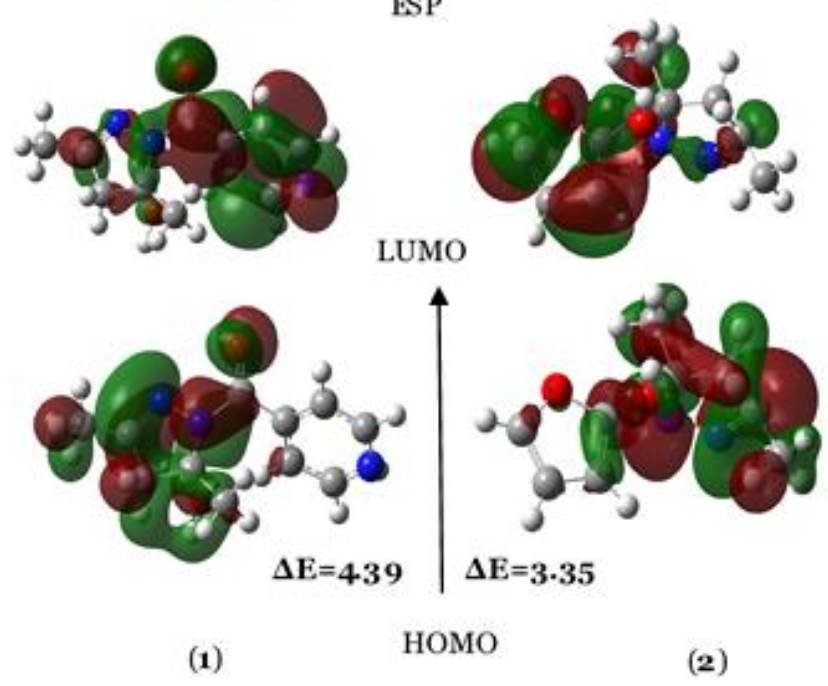

Figure 3. Band gap energy and Molecular electrostatic potential for compounds (1) and (2)

\section{F. Molecular docking}

The three-dimensional (3D) structure of DNA gyrase from E. Coli is a special enzyme used in homeostatic control of DNA and the target for antibacterial compounds was obtained from the Protein Data Bank (PDB ID: 6RKV) (Vande Broeck et al., 2019). All molecular structures were sketched in ChemDraw ultra-version 17.1 (2017) and were submitted to 
Chem3D Ultra Visualizing program to obtain standard 3D structure in (pdb) format. The receptor and ligand files were docked using AutoDock 4.2 along with Auto Dock Tools was used to perform docking simulation. Discovery Studio Visualizer 2017 was employed to analyze the interactions of the studied compounds and to the enzyme.

Docking studies are computational techniques to explore possible modes of ligand and receptor (enzyme) binding, the results of the analysis suggest that the compounds we used for docking exhibited interactions between the hydrogen bonds with target protein. Among these compounds, compound (1) exhibited good inhibition activity against the protein $6 \mathrm{RKV}$ is indicated by its lower binding energy value $5.29 \mathrm{kcal} / \mathrm{mol}$ and hi forms one hydrogen bond, the residue involved in the interaction with compound is with Met 111. we also notice that the oxygen of furan ring in the compound (2) is produced hydrogen bonds interaction with Val 268 and Hhe 96, respectively, but the $\mathrm{N}$ atom of the pyridine fraction did not make any hydrogen bond which shows that our explanation by the theoretical DFT method is really correct, the oxygen atom more electronegative than nitrogen therefore the antibacterial activity increases in molecules that contain several electronegative atoms. The docking conformation of more active compound (2) with furan ring and pyrazole substituted by hydroxyl showed a good interaction as well as a good docking score $(-6.07 \mathrm{kcal} / \mathrm{mol})$. However, in the present study, the molecular docking of the synthesized compounds was carried out to study their binding pattern with DNA gyrase and compare them with a standard inhibitor (Ampicillin) which exhibited moderate inhibitory activity against the $6 \mathrm{RKV}$ protein is indicated by its lower binding energy value of $4.82 \mathrm{kcal} / \mathrm{mol}$. The docking results are shown in (Table 3 ).

Table 3. Calculated binding affinity values between proteins $6 \mathrm{RKV}$ and ligands

\begin{tabular}{|c|c|c|c|c|c|}
\hline Compound & $\begin{array}{c}\text { Free } \\
\text { Energy of } \\
\text { Binding } \\
\text { Kcal } / \mathrm{mol}\end{array}$ & $\begin{array}{l}\text { Inhibition } \\
\text { constant } \\
\text { at } 298.15 \\
\mathrm{~K}(\mu \mathrm{M})\end{array}$ & $\begin{array}{c}\mathrm{H}- \\
\text { bonds }\end{array}$ & $\begin{array}{c}\text { Interaction } \\
\text { residues of } \\
\text { 6RVK }\end{array}$ & $\begin{array}{l}\text { Hydrophobic } \\
\text { interactions }\end{array}$ \\
\hline (1) & -5.29 & 132.02 & 1 & Met 101 & $\begin{array}{c}\text { Phe } 513, \mathrm{Tyr} \\
\text { 100, Ile } 130, \mathrm{Ala} \\
128,\end{array}$ \\
\hline (2) & -6.07 & $35 \cdot 32$ & 3 & $\begin{array}{l}\text { Val 268, Phe } \\
96, \text { Gln 276 }\end{array}$ & $\begin{array}{c}\text { Gln } 276, \text { Try } \\
266 \text {, Phe } 96 \text {, Ile } \\
112 \text {, Ile } 264\end{array}$ \\
\hline Ampicillin & -4.82 & 290.62 & 4 & $\begin{array}{l}\text { Asp 36, Arg } \\
46, \text { Asp157 }\end{array}$ & $\begin{array}{c}\text { Pro } 43, \operatorname{Arg} 47, \\
\text { Asp } 157\end{array}$ \\
\hline
\end{tabular}

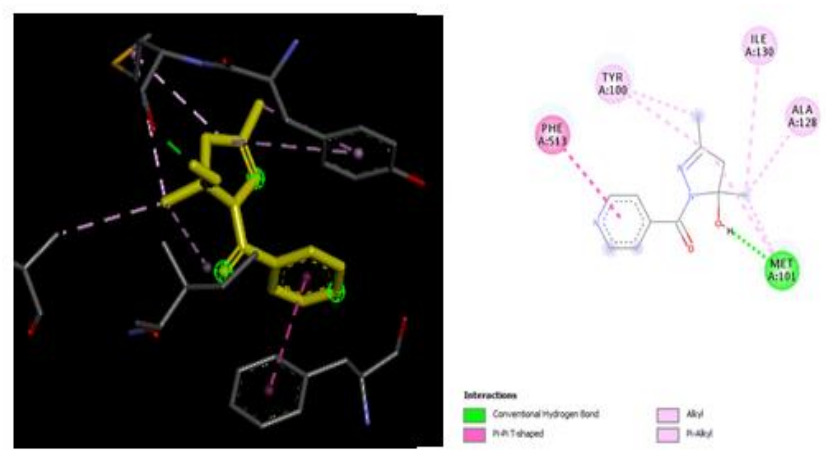

Figure 4. 3D and 2D docking pose showing interaction for compound (1) in the binding site of DNA gyrase (PDB ID: $6 \mathrm{RKV})$
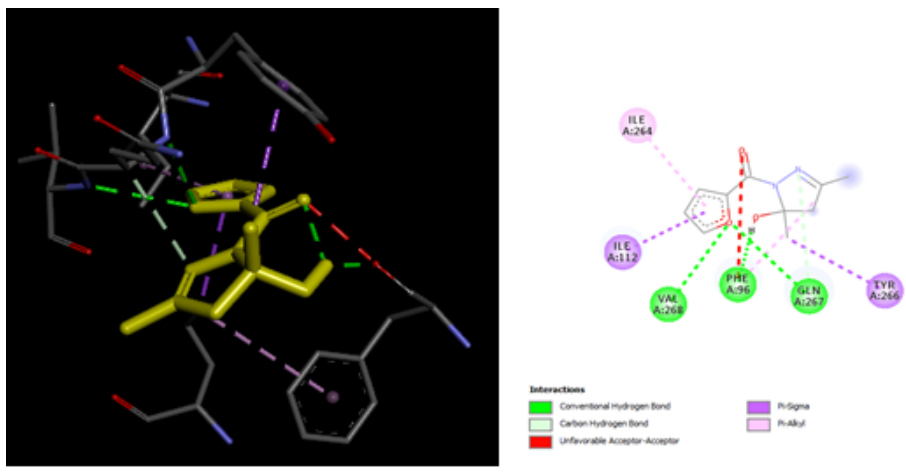

Figure 5. 3D and 2D docking pose showing interaction for compound (2) in the binding site of DNA gyrase (PDB ID: 6RKV)
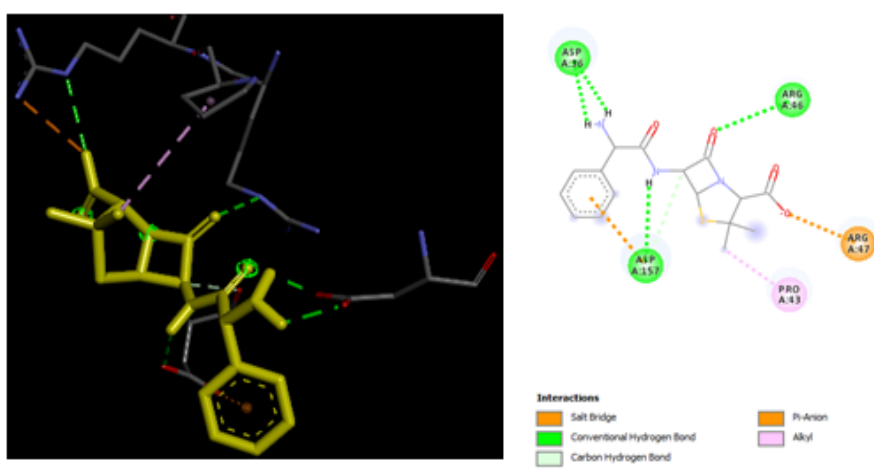

Figure 6. 3D and 2D docking pose showing interaction for Ampicillin in the binding site of DNA gyrase (PDB ID: $6 \mathrm{RKV})$ 


\section{CONCLUSION}

In this study, the synthesis of two derivatives pyrazole trisubstituted was performed and all these compounds synthesized showed promising moderate antibacterial and antioxidant activity. Density functional theory DFT/ B3LYP with the basic set 6-311+ G (p, d). Calculations were carried out to study molecular structures, vibrational spectra, HOMO-LUMO and photophysical properties, and we tried to find a relation between the biological activities results and the theoretical data. Docking results revealed that compound (2) had least binding energy against the $6 \mathrm{RKV}$ receptor with a binding energy value of $-6.07 \mathrm{kcal} / \mathrm{mol}$. in silico, the results indicate that molecular docking studies were related with experimental results of antibacterial activity.

\section{ACKNOWLEDGEMENT}

The author would like to thank all the people who helped to carry out this work such as ${ }^{1} \mathrm{H}$ NMR, ${ }^{13} \mathrm{C}$ NMR and IR.

\section{REFERENCES}

Arfan M, Tahir MN, Khan R, Sabaa S, \& Iqbal MS 2009, '(2Aminophenyl) [(5S)-5-hydroxy-3,5-dimethyl-4,5 dihydro1H-pyrazol-1-yl]-methanone', Acta Crystallographica Section E, vol. 65, pp. 1834-1835.

Celikel N \& Kavas G 2008, 'Antimicrobial properties of some essential oils against some pathogenic microorganisms', Czech Journal of Food Sciences, vol. 26, pp. 174-181.

Choi CH \& Kertesz M 1997, 'Conformational information from vibrational spectra of styrene, trans-stilbene, and cisstilbene', The Journal of Physical Chemistry, vol. 101, pp. 3823-3831.

Dennington RD, Keith TA, Millam JM 2008, GaussView 5.o.8, Gaussian Inc.

Flores AFC, Rosales PE, Malavolta JL, Flores DC, Malavolta JL \& Flores DC 2014, 'Efficient synthesis of new biheterocyclic 5-[(5-Trifluoromethyl-5-hydroxy-4,5dihydro-1H-pyrazol-1-yl)-1-propan-1-one-3-yl]-2-methyl7-trifluoromethylpyrazolo[1,5-a]pyrimidines', Journal of the Brazilian Chemical Society, vol. 25, pp. 1439-1445.

Frisch MJ, Trucks GW, Schlegel HB, Scuseria GE, Robb MA, Cheeseman JR, Montgomery JA, Vreven J, Kudin T, Burant KN, Millam CJ, Iyengar JM, Tomasi SS, Barone J, Mennucci V, Cossi B, Scalmani M, Rega G, Petersson N, Nakatsuji GA, Hada H, Ehara M, Toyota M, Fukuda K, Hasegawa R, Ishida J, Nakajima M, Honda T, Kitao Y, Nakai O, Klene H, Li M, Knox X, Hratchian JE, Cross HP, Adamo JB, Jaramillo C, Gomperts J, Stratmann R, Yazyev RE, Austin O, Cammi AJ, Pomelli R, Ochterski C, Ayala JW, Morokuma PY, Voth K, Salvador GA, Dannenberg P, Zakrzewski JJ, Dapprich VG, Daniels S, Strain AD, Farkas MC, Malick O, Rabuck DK, Raghavachari AD, Foresman K,
Ortiz JB, Cui JV, Baboul Q, Clifford AG, Cioslowski S, Stefanov J, Liu BB, Liashenko G, Piskorz A, Komaromi P, Martin I, Fox RL, Keih DJ, Al-Laham T, Peng MA, Nanayakkara YC, Challacombe A, Gill M, Johnson PMW, Chen B, Wong W, Gonzalez MW, \& Pople C 2003, Gaussian 03, Gaussian Inc., Pittsburg, PA.

Gece G 2008, 'The use of quantum chemical methods in corrosion inhibitor studies', Corrosion Science, vol. 50, pp. 2981-2992.

Gonzalez C \& Schlegel HB 1990, 'Reaction path following in mass-weighted internal coordinates', Journal of Physical Chemistry, vol. 94, pp. 5523-5527.

Karrouchi K, Radi S, Ramli Y, Taoufik J, Mabkhot YN, Alaizari FA \& Ansar M 2018, 'Synthesis and pharmacological activities of pyrazole derivatives: a review', Molecules, vol. 23, pp. 134-150.

Khan MF, Alam MM, Verma G, Akhtar W, Akhter M \& Shaquiquzzaman M 2016, 'The therapeutic voyage of pyrazole and its analogs: A review', European Journal of Medicinal Chemistry, vol. 120, pp. 170-201.

Lee C, Yang W \& Parr RG 1988, 'Development of the ColleSalvetti correlation-energy formula into a functional of the electron density', Physical Review B, vol. 37, pp. 785-789.

Leitao G, Leitao SG, \& Vilagag W 2002, 'Quick preparative separation of natural Naphtopyranones with antioxidant activity by high-speed counter-current chromatography', Z. Naturforsch Journal, vol. 57, pp. 1051-1055.

Mulliken RS 1934, 'New electroaffinity scale; together with data on valence states and on valence ionization potentials and electron affinities', Journal of Chemical Physics, vol. 2, pp. 782-793. 
Nimbalkar S, \& Hote SV 2015, 'Pyrazole Derivatives and their Synthesis-A review', International Journal on Recent and Innovation Trends in Computing and Communication, vol. 3, pp. 61- 65.

Pearson RG 1985, 'Absolute electronegativity and absolute hardness of Lewis acids and bases', Journal of the American Chemical Society, vol. 107, pp. 6801-6806.

Shah NS, Biradar A, Habib SI, Dhole J, Baseer M \& Kulkarni $P$ 2011, 'Synthesis and antimicrobial studies of some novel pyrazolines', Der Pharma Chemica, vol. 3, pp. 167-171.

Vande Broeck A, Lotz C, Ortiz J, \& Lamour V 2019, 'Cryo-EM structure of the complete E. coli DNA gyrase nucleoprotein complex', Nature Communications, vol. 10, pp. 4935-4935.

Venkateswarlu V, Kour J, Aravinda Kumar KA, Verma PK, Reddy GL, Hussain Y, Tabassum A, Balgotra S, Gupta S, Hudwekar AD, Vishwakarma RA \& Sawant SD 2018, 'Direct $\mathrm{N}$-heterocyclization of hydrazines to access styrylated pyrazoles: synthesis of 1,3,5-trisubstituted pyrazoles and dihydropyrazoles', RSC Advances, vol. 8, no. 47, pp. 2652326527.

Zhan CC, Nichols JA \& Dixon DA 2003, 'Ionization potential, electron affinity, electronegativity, hardness, and electron excitation energy: molecular properties from density functional theory orbital energies', Journal of Physical Chemistry A, vol. 107, pp. 4184-4195. 